\title{
Survival of the Recidivistic? Revealing Factors Associated with the Criminal Career Length of Multiple Homicide Offenders
}

\author{
Gian Maria Campedelli ${ }^{\ddagger}, \quad$ Enzo Yaksic ${ }^{2}$ \\ $\ddagger$ Corresponding Author: gianmaria.campedelli@unitn.it \\ ${ }^{1}$ Department of Sociology and Social Research - University of Trento, Italy \\ ${ }^{2}$ Atypical Homicide Research Group, Boston, MA, USA
}

\begin{abstract}
Relying on a sample of 1,394 US-based multiple homicide offenders (MHOs), we study the duration of the careers of this extremely violent category of offenders through KaplanMeier estimation and Cox Proportional Hazard regression. We investigate the characteristics of such careers in terms of length and we provide an inferential analysis investigating correlates of career duration. The models indicate that females, MHOs employing multiple methods, younger MHOs and MHOs that acted in more than one US state have higher odds of longer careers. Conversely, those offending with a partner and those targeting victims from a single sexual group have a higher probability of shorter careers.
\end{abstract}

Keywords: Serial Homicide; Survival Analysis; Criminal Careers; Cox Proportional Hazards Regression 


\section{Introduction}

Empirical research on multiple homicide offenders (MHOs) has revealed many dynamics behind the motives, actions and outcomes of the criminal activities of this widely debated and low-prevalence typology of offenders. The fascination of media and society with serial killers and murderers contributed to the development of myths and misleading narratives that scholars are contributing to falsify (Hickey, 2015). In spite of the numerous works investigating the characteristics of MHOs, however, still no works exist that comprehensively investigate the length of the careers of MHOs and, more specifically, the determinants and correlates of their duration. While duration is a central concept in the study of criminal careers, and it has been analyzed in reference to very distinct criminal and delinquent samples (Blumstein and Cohen, 1987; Rhodes, 1989; Piquero et al., 2004; Campedelli et al., 2019), its relevance for MHOs has been overlooked so far, especially from a quantitative point of view. This study specifically seeks to fill this gap by studying the career duration of a large sample comprising 1,394 MHOs based in the United States.

Relying on the data gathered from the Consolidated Serial Homicide Offender Database, we consider MHOs as those offenders that committed at least two homicides in two separate events, thus including both serial murderers and spree killers, embracing an inclusive definitional approach as proposed also by Delisi and Scherer (2006). To shed light on the characteristics of career length across the sample and the factors associated with its duration, we employ survival analysis, and specifically Kaplan-Meier estimation (Kaplan and Meier, 1958) and Cox Proportional Hazard regression (Cox, 1972), two well-known methodological approaches frequently utilized in the health sciences which have also gained gained popularity in criminology.

The evidence reported in the present work indicates that, within the broad category of MHOs, there exist many layers of heterogeneity in terms of career duration. Several variables, both at the individual and criminal level, are able to explain and characterize the differences arising in the sample. The findings aim to contribute to the academic literature on the topic and seek also to provide possible directions to law enforcement agencies (LEAs). Being able to probabilistically predict the number of years an MHO will be active by exploiting the available information gathered during the investigations may help to circumscribe the number of options on suspects. Furthermore, and more 
importantly, it would facilitate the designation of strategies to optimally deploy material and immaterial resources in the attempt to stop serial killing activity.

\section{Background}

Early efforts to understand MHOs uncovered the separate "other life" that many construct which affords them the ability to remain beyond scrutiny and free to kill (DeLisi, 2015). Because criminal careers progress in intermittent and unpredictable ways (DeLisi et al., 2019), few studies have considered the activities MHOs engage in as being a serious and meaningful pursuit, and fewer would label these endeavours as a career. As an $\mathrm{MHO}$ is defined as someone that has killed at least two people over a period of time, the temporal component implies persistency over at least a fraction of the offender's life course. Although multiple murders are often carried out as a coping strategy, these homicides usually occur in the context of a long criminal history Miller (2014) as episodes embedded within a larger criminal career (Delisi and Scherer, 2006). A large percentage of MHOs have arrest records (Harbort and Mokros, 2001; Beasley, 2004; Sturup, 2018; James et al., 2019): Delisi and Scherer (2006), for instance, found that $32 \%$ of MHOs were career criminals before they committed their homicides. Many MHOs are also involved in nonlethal crimes unrelated to their series (Schlesinger et al., 2017; Sturup, 2018; DeLisi et al., 2019).

MHOs distinguish themselves from other criminals due to their commitment (Williams, 2017b) to translating their defiance of social institutions and dissatisfaction with their lives into a long-term killing career (Williams, 2017b; DeLisi et al., 2019; James et al., 2019). Their thought patterns, hostile and aggressive personalities, and negative perception of the world result in trajectories punctuated by criminal behavior (James et al., 2019; Yaksic, 2019). Developmental problems contribute to deviant behaviors but they do not necessarily deter offenders from pursuing a criminal career (Beasley, 2004). Since there is some amount of versatility and sophistication necessary to continue as a habitual offender in a heavily policed world, organized offenders survive by avoiding behaviors that might increase their chances of apprehension and by relying on resilience and luck to overcome obstacles. As MHOs refine their skills and abilities (Williams, 2017a) and learn to specialize in homicide offending, they may be repelled 
by or attracted to certain crimes (DeLisi et al., 2019). This type of selection process has implications for the pathways that offenders choose. Once MHOs commit to a particular course, they generally remain consistent in their behavioral theme (Salfati and Bateman, 2005; Pakkanen et al., 2015; Yaksic, 2015) with little escalation in violence (Morton et al., 2014). So while MHOs can be both versatile and specialists, their focus narrows on specific forms of antisocial conduct after taking demographic variations and progression of their career into account (DeLisi et al., 2019).

Although some MHOs strive to kill for decades, and a few have shown a lifelong pattern of antisocial and criminal behavior (Miller, 2014), only a small number of MHOs kill for extended time spans, over many years. Although Arndt et al. (2004) estimated the average career length of MHOs to four to five years, Quinet (2011) found that the killing career of MHOs has decreased from a high of 9.3 years in the 1970s to 2.2 years by 2009, while Gurian (2017) found that male MHOs commit their murders in two years or less. The variable length of an MHO's career is impacted by many factors that also influence the span of intervals between killings. The presence or absence of police surveillance, personality differences, marriage, the influence of a partner, or geographic factors (Lange, 1999), and daily activities (Osborne and Salfati, 2014) can impact the MHO's engagement with deviant behavior. Location (DeFronzo et al., 2007), social controls such as employment, attachments (Liem, 2013; Osborne and Salfati, 2014), personal choices such as body disposal, victim type, and crime scene actions (Quinet, 2011; Reale and Beauregard, 2019; James and Beauregard, 2020), exogenous contextual circumstances such as the thoroughness of the investigation (LePard et al., 2015; James and Beauregard, 2020) all also play a role in the success of MHO's criminal activities.

Multiple homicide research is increasingly interested in outcomes (e.g., body count) rather than the background operations that transpire to effect career duration. Thusly, MHO research lacks a clear understanding of the correlates related to the length of these careers. This work is inspired by Harbort and Mokros (2001) call for studies that use the elapsed time span between the offender's first homicide and their apprehension as a measure to investigate MHOs and continued signs of deviance. We hence investigate how long MHOs operate and whether or not their attributes and the characteristics of their events can predict how long these individuals will continue to commit mur- 
ders. The current study uses survival analysis and Cox probabilistic regression models to analyze the duration of the career of each MHO by looking at the relevant differences between them in terms of socio-demographic data and operational career-related patterns.

\section{Materials and Methods}

\section{Sample Selection}

Data are retrieved from the Consolidated Serial Homicide Offender Database. The dataset is the product of merged records from independently built databases maintained and contributed by members of the Atypical Homicide Research Group, the Serial Homicide Expertise and Information Sharing Collaborative and the Homicide Investigation Tracking System of the Washington State Attorney General's Office. In its original form, the database includes 4,802 cases of MHOs from all over the world. With each individual are associated demographic, socio-economic, contextual and criminal information that allow for the consideration of both the features of the homicide series (e.g., type of victims, methods, states in which the offender was active) and the individual characteristics of the offender (e.g., year of birth, gender, age at first homicide, prior contacts with the criminal justice system).

For the purposes of the present work, we have considered only those MHOs that acted in the United States, and we have removed all those cases labeled as either "suspected" or "accused", in order to avoid including individuals for which investigations may not lead to a sentence. Furthermore, we have selected only those MHOs for which data on previous contacts with the criminal justice system were available, reducing the total number of offenders from 2,908 to 1,394 . The choice was made because among the covariates selected for the inferential analyses, "prior criminal history" was the one reporting the highest rate of missing data in the original dataset, compared to all the others (52.06\%). Given the architecture of the paper, which revolves around a tripartite modeling structure, the unbalanced number of observations across models could have reduced the validity of the findings. We have then included data on previous arrests as an inclusion criterion for the sample creation. Once uncertain or incomplete cases were excluded, we have calculated the duration $D$ of the career by computing: 


$$
D=\left(Y_{T}-Y_{1}\right)+1
$$

Where $Y_{T}$ is the year in which the last known homicide was committed, and $Y_{1}$ is the year in which the first one was perpetrated. A year is finally added to ensure that career duration of offenders that committed their first and last crime in the same year is not computed as 0 . After the calculation of duration, four cases for which the value could not be estimated (due to either $Y_{1}>Y_{T}$ or $Y_{T}>>Y_{1}$ ) have been filtered out from the dataset, leading to a final sample of 1,394 MHO.

\section{Methodology}

To study the dynamics behind the career duration of MHOs we have applied Survival analysis through the estimation of the survival function using Kaplan-Meier estimation (Kaplan and Meier, 1958) and Cox Proportional Hazard Regression (Cox, 1972). Survival analysis is a statistical method that allows for the measurement of individuals' lifespans. Originally, it was mostly used in health-care to understand, for instance, patients' responses to treatment or reactions to diseases, over time (Wilschanski et al., 1995; Singh and Mukhopadhyay, 2011; MacKenzie et al., 2014). Its popularity, however, transcends the boundaries of medicine, and it is currently used in many domains (Laitinen, 2005; Giot and Schwienbacher, 2007; Golub, 2007; Darmofal, 2009; BoxSteffensmeier et al., 2015), including criminology (Smith and Akers, 1993; Marshall and English, 1999; Benda, 2005). In our case, we measure the duration of the careers of MHOs, a specific category of offenders defined by the commission of at least two homicides over the course of each individual's life.

As a first step, the survival function for the entire population is computed as a baseline to describe the distribution of career duration for all individuals in the sample. While in many other research applications, at the time of the analyses, not all deaths (or conclusive events of any other sort) have occurred yet, thus needing censoring, all the individuals included in the our sample are either deceased or imprisoned, naturally representing closed careers.

Considering $T$, a non-negative random lifetime taken from our sample of MHO, representing the time these offenders are active, then the survival function $S(t)$ is defined as: 


$$
S(t)=P(T>t)
$$

This function simply describes the probability that the career is not concluded at time $t$. There are several ways to estimate a survival function. Our models use Kaplan-Meier Estimate, which is calculated as:

$$
\hat{S}=\prod_{t_{i}<t} \frac{n_{i}-d_{i}}{n_{i}}
$$

where $d_{i}$ represents the number of career closures at time $t$, while $n_{i}$ is the number of subjects at risk of having their careers terminated before $t$.

Our data also allow us to further investigate how covariates influence the duration of the MHOs' careers. As a second step, therefore, we have hence applied Cox proportional hazard regression - a semiparametric model - with the hazard function at any given time representing the dependent variable. Cox proportional hazard regression models the log-hazard of an individual as a linear function of static covariates (e.g., Race) and a population-level baseline hazard that is updated at every time-step. In mathematical terms, the hazard rate is defined by:

$$
h(t, \mathbf{X})=h_{0}(t) \exp ^{\sum_{j=1}^{p} \beta_{j} X_{j}}
$$

where $h_{0}(t)$ is the time component, also called baseline hazard function, while the second part of the product, $\exp ^{\sum_{j=1}^{p} \beta_{j} X_{j}}$, named partial hazard, is an exponentiated time-invariant factor in the form of a linear function of $p$ covariates $X$ that can either decrease or increase the baseline hazard. Cox regression is not the only candidate method for performing inferential analyses of survival curves. Parametric models are also common in the literature (Hjort, 1992; Royston and Parmar, 2002; Lambert and Royston, 2009). However, while such models require to specify a certain distribution for the survival times (e.g., Weibull, Gompertz), Cox regression has higher flexibility since the baseline hazard function does not have to be restricted to a specific form. Nonetheless, the model assumes proportional hazards, meaning that the hazard for two subjects $i$ and $j$ are proportionally fixed over-time, and hence:

$$
\frac{h_{i}\left(t \mid \mathbf{X}_{i}\right)}{h_{j}\left(t \mid \mathbf{X}_{j}\right)}=\exp \left(\beta\left(\mathbf{X}_{i}-\mathbf{X}_{j}\right) h_{j}\left(t \mid \mathbf{X}_{j}\right)\right)
$$


The literature has shown the risks and statistical issues associated with the practice of ignoring this assumption (Vatcheva et al., 2015; Rulli et al., 2018). Therefore, in the present work, we have tested the proportional hazard assumption through Schoenfeld residuals. Furthermore, given the possibility to add penalization to a regression model, we have tested selected the best models using Akaike Information Criterion (AIC) (Akaike, 1974). ${ }^{1}$

\section{Covariates}

Factors associated with career duration in MHOs are analyzed from three perspectives. A first model only considers offenders' individual-level attributes that are inherently non-criminal, the second model includes crime-related information. Finally, the third combines them to provide a more comprehensive and robust picture on factors linked with career duration. Individual-level attributes are the offender's sex, race and age. Crime-related variables instead map the number of victims, the presence of a killing partner, the race of the offender's victims, the sex of the offender's victims, the use of multiple killing methods, state mobility, the presence of prior arrests, and having targeted at least one child over the entire career.

\section{Individual-level Attributes}

Sex. Scholarly research has shown that the vast majority of MHOs are male (Hickey, 2015). However, there exists a relevant number of women within the selected sample. While research has tried to focus on the characteristics of female MHOs (Keeney and Heide, 1994; Kelleher and Kelleher, 1998; Häkkänen-Nyholm et al., 2009; Gurian, 2017; Fridel, 2019), also in comparison with men, the relationship between gender and career duration for MHO is still unclear and overlooked in the literature.

Race. While white individuals account for the vast majority of MHOs in history, the literature has highlighted how MHOs come from multiple racial backgrounds (Fox and Levin, 1994; Egger, 1997; Delisi and Scherer, 2006; Branson, 2013). The individuals in our sample reflect this diversity. For this reason, we have included a categorical variable mapping four groups: White (treated as baseline given their higher frequency), Black,

\footnotetext{
${ }^{1}$ All analyses are performed using the Python library Lifelines (Davidson-Pilon et al., 2020).
} 
Hispanic and a residual category combining together Asians and Natives (this decision was driven by the low frequency of MHOs belonging to these two groups).

Age. The age of onset is one of the most investigated topics in criminal careers research. Here, we study the age at the first homicide by considering the variable in a continuous form (Delisi and Scherer, 2006; Piquero et al., 2007; Vaughn et al., 2009; Farrington et al., 2014). We are interested in investigating whether starting to kill earlier is associated with longer careers or not. A first logical viewpoint proffers that the earlier MHOs start, the higher the potential number of years to commit criminal acts. However, an alternative hypothesis sees the higher number of years to commit criminal acts as a risk factor linked to the theoretically increased probability of careertermination due, for instance, to LEAs successful investigation activities.

\section{Career-related Variables.}

Number of victims. While several studies have addressed the differences between single-victim homicide offenders and MHOs (Hill et al., 2007; Trojan and Salfati, 2010; Sturup, 2018), there is no research on the correlation link between the number of victims and the duration of the homicide trajectory of an offender. Here we are interested in assessing whether the higher the number of victims, the shorter the career due to the increased risk for errors and the disproportionate attention and pressure of LEAs.

Killing Partner. Extant works indicate that the presence of a killing partner in committing homicide affects the dynamics of the act itself (Juodis et al., 2009; Gurian, 2017). In this study, we ask whether acting in partnership with another individual has a relationship with career duration. The hypothesis is that offenders acting with a partner are more exposed to the risk of being caught by LEAs due to the possibility that their partner discontinues their loyalty and informs on the team's activities.

Sex of Victims. Previous research has studied the gender of the victims as a fundamental element capable of shedding light on the existing typologies of MHOs, indicating that women are generally the preferred and more frequent target (Kraemer et al., 2004; Pakhomou, 2004; Quinet, 2011). Therefore, a binary variable in the present study is included to define the role of the sex of victims in a homicide series in relation to the 
duration of the career: having killed only either men or women vs having killed both sexes.

Race of Victims. Serial homicide is generally intra-racial, meaning that offenders from a given racial group tend to target individuals belonging to the same group (Fox and Levin, 1998; Hickey, 2015). Nonetheless, there is a minority of MHOs that commit their actions against people of different races (Chan et al., 2010; Salfati et al., 2015). To explore whether this aspect has any connection with the duration of a career, we have included a binary variable mapping this distinction. Given the patterned behavior of MHOs with respect to victims' race, those killing people from different racial groups might go more easily undetected, exploiting their anomalous nature compared to that of the dominating sub-sample.

Targeting Children. There exists a plethora of studies investigating the relationship and motivations behind the selection of children as victims of violent crimes (Widom, 1989; Hanson et al., 1993; Greenfield, 1996; Mitchell and Aamodt, 2005; Beauregard et al., 2008; Spehr et al., 2010; Mathews et al., 2013; Stöckl et al., 2017). Explanations drawing upon social, subcultural and psychological theoretical frameworks have been proposed to shed light on this topic. Nonetheless, the question of whether we can establish an association between targeting children and career duration has gone mostly unanswered so far. Given previous findings that have shown that homicides involving younger victims tend to be solved more quickly compared to others (Beauregard and Martineau, 2014), our hypothesis is that targeting children throughout a career constitutes a risk factor for early-career termination.

Killing Method. Academic research has dedicated great attention to the killing methods employed by MHOs (Fox and Levin, 1994; Keeney and Heide, 1994; Hickey, 2015; Sturup, 2018). In many cases, the method is repeated and acquires a relevant role in the investigative process. The presence of a unique method, in fact, may facilitate agencies in the investigative action. Accordingly, a dichotomous variable describes whether the offender only commits homicides through a single methodology or employs multiple ones. 
State Mobility. As demonstrated by previous studies, mobility represents a relevant factor in shaping serial offenders' (including MHOs) actions (Canter and Larkin, 1993; Snook et al., 2005). Besides the theoretical and empirical findings related to the dynamics connecting offenders' home and the place where a crime is committed, mobility in the current study is relevant especially as a potential obstacle to effective LEA investigations. Such an impending factor might in fact be connected to longer careers (Council, 2009; Kelty et al., 2013).

Prior Arrests. The presence of criminal records represents a well-debated element in the study of MHOs, due to the mixed nature of findings from different studies (Egger, 1997; Harbort and Mokros, 2001; Delisi and Scherer, 2006; Miller, 2014; Hickey, 2015; Trojan and Salfati, 2016). To attempt to contribute to this line of research, in this study we include a dichotomous variable that separates those MHOs with at least one previous arrest before the commission of the first murder and those that, instead, did not have any criminal record.

Table 1 describes all the covariates included in the model, briefly explaining their distribution and composition, reporting also the share of missing data.

\section{Results}

\section{Survival Analysis on the Overall Sample}

The median number of years an MHO was active is equal to 3, meaning that after 3 years of activity the $50 \%$ of all careers are terminated, while the average is 6.47 . The estimation is higher than those provided by Kelleher and Kelleher (1998) and Jenkins (1994). The function shows that already after one single year of activity, many careers end. Notably, a tiny minority of offenders are however able to keep committing murders for extremely long time spans. The longest one, specifically, covers a total of 51 years. Figure 1 displays the distribution of duration across the sample. Figure 2 provides instead a visualization of the Kaplan-Meier curve for the considered sample.

Given the high heterogeneity present in the whole distribution of duration, we argue that there may be an array of factors able to explain such differences, at least partially. As MHOs exhibit very distinct characteristics, in spite of many false narratives reinforced 
Table 1: Description of covariates (along with missing values)

\begin{tabular}{|c|c|c|c|}
\hline Dimension & Variable & Distribution & $\begin{array}{c}\text { N } \\
\text { Missing }\end{array}$ \\
\hline \multirow{3}{*}{$\begin{array}{l}\text { Individual } \\
\text { Attributes }\end{array}$} & Sex & $1,286(92.25 \%)$ are men, $108(7.75 \%)$ are women & $\begin{array}{c}0 \\
(0 \%)\end{array}$ \\
\hline & Age & $\begin{array}{l}\text { The average age at first homicide is } 27.62(\mathrm{SD}=8.73) \text {. } \\
\text { The median value is } 26 \text {. }\end{array}$ & $\begin{array}{c}16 \\
(1.15 \%)\end{array}$ \\
\hline & Race & $\begin{array}{l}813 \text { were white }(58.32 \%), 483(34.65 \%) \text { black, } \\
68(4.88 \%) \text { Hispanic and } 24(1.72 \%) \text { were either } \\
\text { natives or Asian. }\end{array}$ & $\begin{array}{c}6 \\
(0.43 \%)\end{array}$ \\
\hline \multirow{10}{*}{$\begin{array}{l}\text { Career-focused } \\
\text { variables }\end{array}$} & $\begin{array}{l}\mathrm{N} \text { of } \\
\text { Victims }\end{array}$ & $\begin{array}{l}\text { On average, each } \mathrm{MHO} \text { has killed } 4.81 \text { victims }(\mathrm{SD}=4.91) \text {. } \\
\text { The minimum is } 2 \text {, the maximum is } 54 \text {. }\end{array}$ & $\begin{array}{c}1 \\
(0.07 \%)\end{array}$ \\
\hline & $\begin{array}{l}\text { Victims' } \\
\text { Race }\end{array}$ & $\begin{array}{l}883(63.34 \%) \text { targeted a single racial group, } \\
345(24.75 \%) \text { murdered individuals from multiple races }\end{array}$ & $\begin{array}{c}166 \\
(11.91 \%)\end{array}$ \\
\hline & $\begin{array}{l}\text { Children } \\
\text { Victims }\end{array}$ & $\begin{array}{l}1,155(82.86 \%) \text { did not target children, } \\
233(16.71 \%) \text { did instead. }\end{array}$ & $\begin{array}{c}6 \\
(0.43 \%)\end{array}$ \\
\hline & Killing & $1,133(81.28 \%)$ did not act with a partner, & 11 \\
\hline & Partner & $250(17.93 \%)$ had one. & $(0.79 \%)$ \\
\hline & $\begin{array}{l}\text { State } \\
\text { Mobility }\end{array}$ & $\begin{array}{l}1,017(72.96 \%) \text { killed in only one US state, } \\
377(27.04 \%) \text { acted in more than one state. }\end{array}$ & $\begin{array}{c}0 \\
(0.00 \%)\end{array}$ \\
\hline & $\begin{array}{l}\text { Prior } \\
\text { Arrests }\end{array}$ & $\begin{array}{l}1,221(87.59 \%) \text { had been arrested prior to killing, } \\
173(12.41 \%) \text { had not. }\end{array}$ & $\begin{array}{c}0 \\
(0.00 \%)\end{array}$ \\
\hline & Multiple & $851(61.05 \%)$ only killed using one method, & 0 \\
\hline & Methods & $543(38.95 \%)$ used multiple ones. & $(0.00 \%)$ \\
\hline & $\begin{array}{l}\text { Victims' } \\
\text { Sex }\end{array}$ & $\begin{array}{l}778(55.82 \%) \text { targeted either men or women only } \\
\text { and } 596(42.75 \%) \text { targeted both sexes. }\end{array}$ & $\begin{array}{c}20 \\
(1.43 \%)\end{array}$ \\
\hline
\end{tabular}

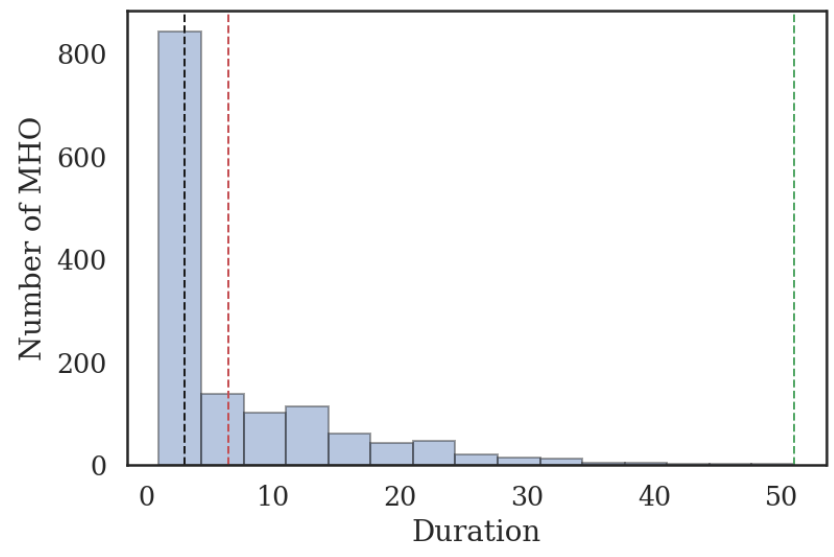

Figure 1: Histogram Representing duration distribution across the sample. Vertical shaded line maps the median value, red shaded line maps the average, green shaded line describes the maximum duration in the sample. 


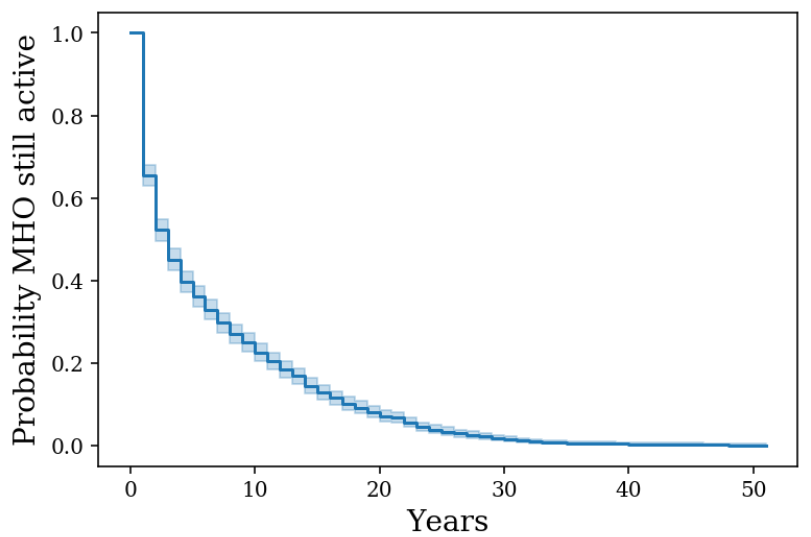

Figure 2: Kaplan-Meier Survival Function Estimate for the entire sample

by novels and fictional accounts (Hickey, 2015), their diverse nature may be reflected in a connection with activity duration. Although the response of the criminal justice system and the intervention of LEAs has certainly a crucial role in incapacitating an offending behavior - and therefore terminating MHOs careers - our intuition is that there are also individual-level attributes and operational features that modify the likelihood of prolonged offending trajectories.

\section{Inferential Analysis: Individual-attributes Model}

As anticipated, individual attributes consider the sex, the age at the time of the beginning of the series, and the race of each MHO. Below, the distribution of duration for each category present in each variable is plotted (Figure 3).

Graphically, there seems to be a clear overlap between density curves especially for the variable describing the offender's sex. More variation in the shapes is displayed by the modes in the age category and the race variable - although this is especially true for the marginal category "Other" which counts very few cases.

We have first fit a baseline model including the listed variables to check for the proportional hazard assumption. Given the large sample, we have fixed the p-value threshold at 0.001. All variables passed the test. At this point, we have tested multiple penalization terms and selected the model with no penalization, as it minimized the AIC score. Results of the test are reported in Table 2. 

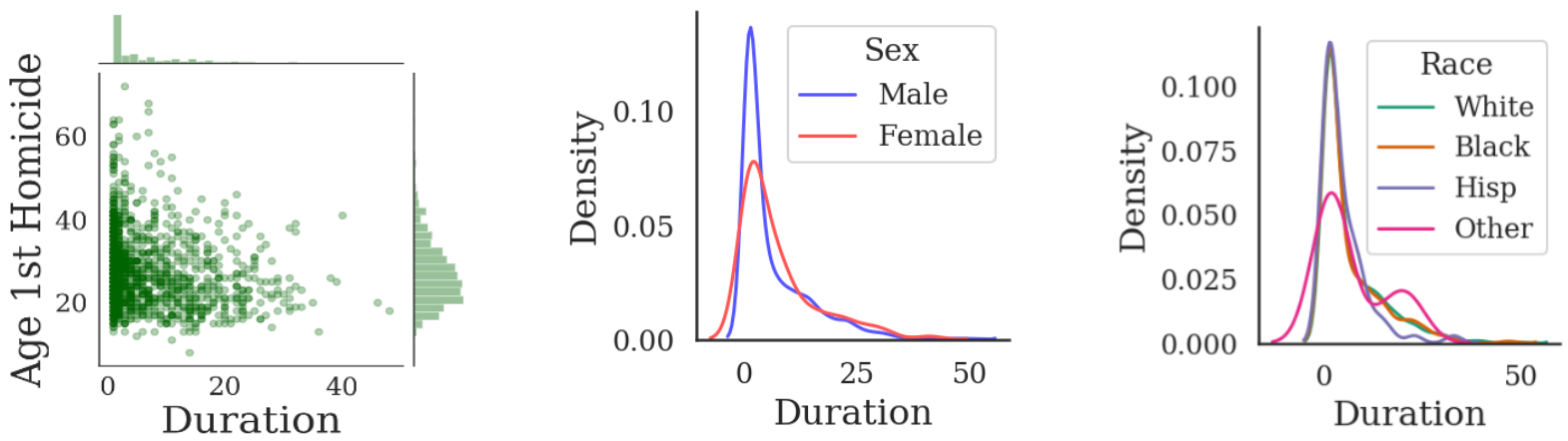

Figure 3: Career Duration Distribution by Age at First Homicide, Sex and Race

Table 2: AIC Results for Model Selection Across different Penalization Terms (Individual Attributes Model) - Asterisk Highlights Best Model

\begin{tabular}{cc}
\hline Penalization Term & AIC \\
\hline 0 & $17049.80^{*}$ \\
0.01 & 17050.34 \\
0.05 & 17052.35 \\
0.5 & 17067.15 \\
1 & 17075.34 \\
5 & 17090.68 \\
\hline
\end{tabular}

Following, Table 3 displays the coefficients for the individual attributes model. Being a male does not have a significant effect on career duration, compared to women. For what concerns age, a unit increase in the age at first homicide increases the probability of career termination by $2 \%$ every year $(\mathrm{HR}=1.02,95 \% \mathrm{CI}=1.01-1.03)$. This indicates that younger MHOs have higher odds of being active for longer periods, as opposed to what was suggested by Myers (2004). In terms of race of the offenders, the only statistically significant difference with white MHOs is found for Hispanic MHOs. When only controlling for age and sex, Hispanic individuals in the sample have a 33\% increase in career termination compared to white ones $(\mathrm{HR}=1.33,95 \% \mathrm{CI}=1.04-1.71)$. The results reported in the table are also displayed visually in Figure 4.

\section{Inferential Analysis: Career-focused Model}

As done for the individual attributes model, we have first checked the proportional hazard assumption. The number of victims failed the test, and we have thus proceeded to modify the functional form of the variable which is characterized by non-linearity. 
Table 3: Cox Regression Model - Individual Level Attributes $(n=1,372)$

\begin{tabular}{lccc}
\hline \multicolumn{1}{c}{ Variable } & $\begin{array}{c}\text { Coef. } \\
(\mathrm{SE})\end{array}$ & $\begin{array}{c}\text { Hazard } \\
\text { Ratio }\end{array}$ & $\begin{array}{c}\text { 95\% C.I. } \\
\text { Hazard Ratio }\end{array}$ \\
\hline $\begin{array}{l}\text { Sex } \\
\text { Male }\end{array}$ & $0.18(0.10)$ & 1.20 & {$[0.95-1.43]$} \\
\hline Age & & & \\
Age at First Homicide & $0.02^{\dagger}(0.00)$ & $1.02^{\dagger}$ & {$[1.01-1.03]$} \\
\hline $\begin{array}{l}\text { Race (Baseline is "White") } \\
\text { Black }\end{array}$ & $0.06(0.06)$ & 1.07 & {$[0.95-1.20]$} \\
Hispanic & $0.29^{* *}(0.13)$ & $1.33^{* *}$ & {$[1.04-1.71]$} \\
Other & $0.03(0.21)$ & 1.03 & {$[0.68-1.54]$} \\
\hline
\end{tabular}

Concordance

0.57

Log-likelihood ratio test

47.98 on $5 \mathrm{df}$

$-\log 2(\mathrm{p})$ of 1l-ratio test

28.06

$\dagger$ Significant at $99.9 \%,{ }^{* * *}$ Significant at $99 \%, * *$ Significant at $95 \%$, *Significant at $90 \%$

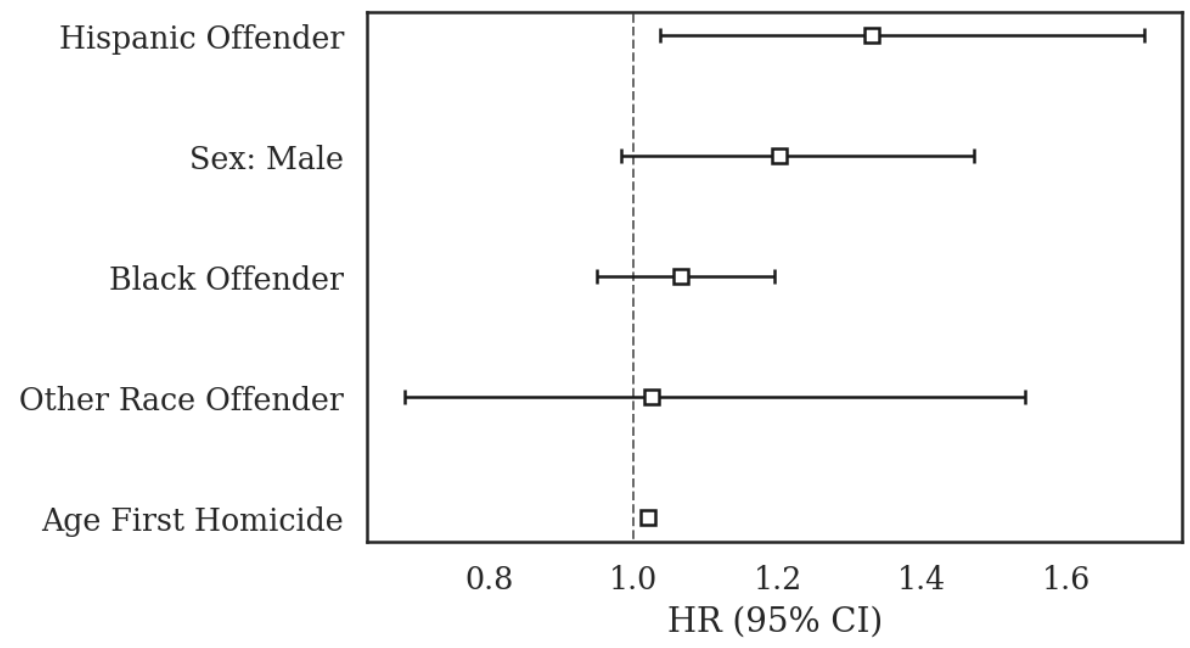

Figure 4: Effect Sizes of Hazard Ratio with 95\% C.I. (Individual Level Attributes)

We have thus coded two additional variables, adding a quadratic and a cubic term to the "Number of victims" variable. After the new test, only the model including the nontransformed and the cubic transformation passed the proportional hazard assumption. In addition, also in this case the model with no penalization was found to be the best, according to the AIC criterion (Table 4).

Career-focused variables try to disentangle the relationship between features and characteristics describing the killing and offending activity and the duration of the career itself. Contrarily to the model concentrating on individual attributes, this one asks 
Table 4: AIC Results for Model Selection Across different Penalization Terms (Career-focused Model) - Asterisk Highlights Best Model

\begin{tabular}{cc}
\hline Penalization Term & AIC \\
\hline 0 & $14762.31^{*}$ \\
0.01 & 14763.69 \\
0.05 & 14768.96 \\
0.5 & 14808.18 \\
1 & 14830.56 \\
5 & 14875.11 \\
\hline
\end{tabular}

whether there are behavioral dynamics that correlate with career length rather than fixed and static attributes that are not inherently connected with the committed offenses. To gain a preliminary flavor of the potential connections between these variables and career duration, Figure 5 shows the kernel density distribution of career duration by criminal attribute.

Besides slight differences, most variables report overlapping normalized density shapes. Only in certain cases, the shapes of the curves suggest a higher share of lengthy careers with respect to a particular mode within a given variable. In this regard, two good examples are the state mobility and the multiple methods curves. In the first case, the density curve mapping MHOs acting in more than one US state shows a prominent share of individuals being active for several decades.

Contrarily, those that only acted in a single state show a steeper decline of the density curve and a far higher share of short careers. A similar graphic results regards MHOs employing multiple killing methods. Concerning the proper inferential models, the results are reported in Table 5. The outcomes reported in the table are also displayed visually in Figure 6. 

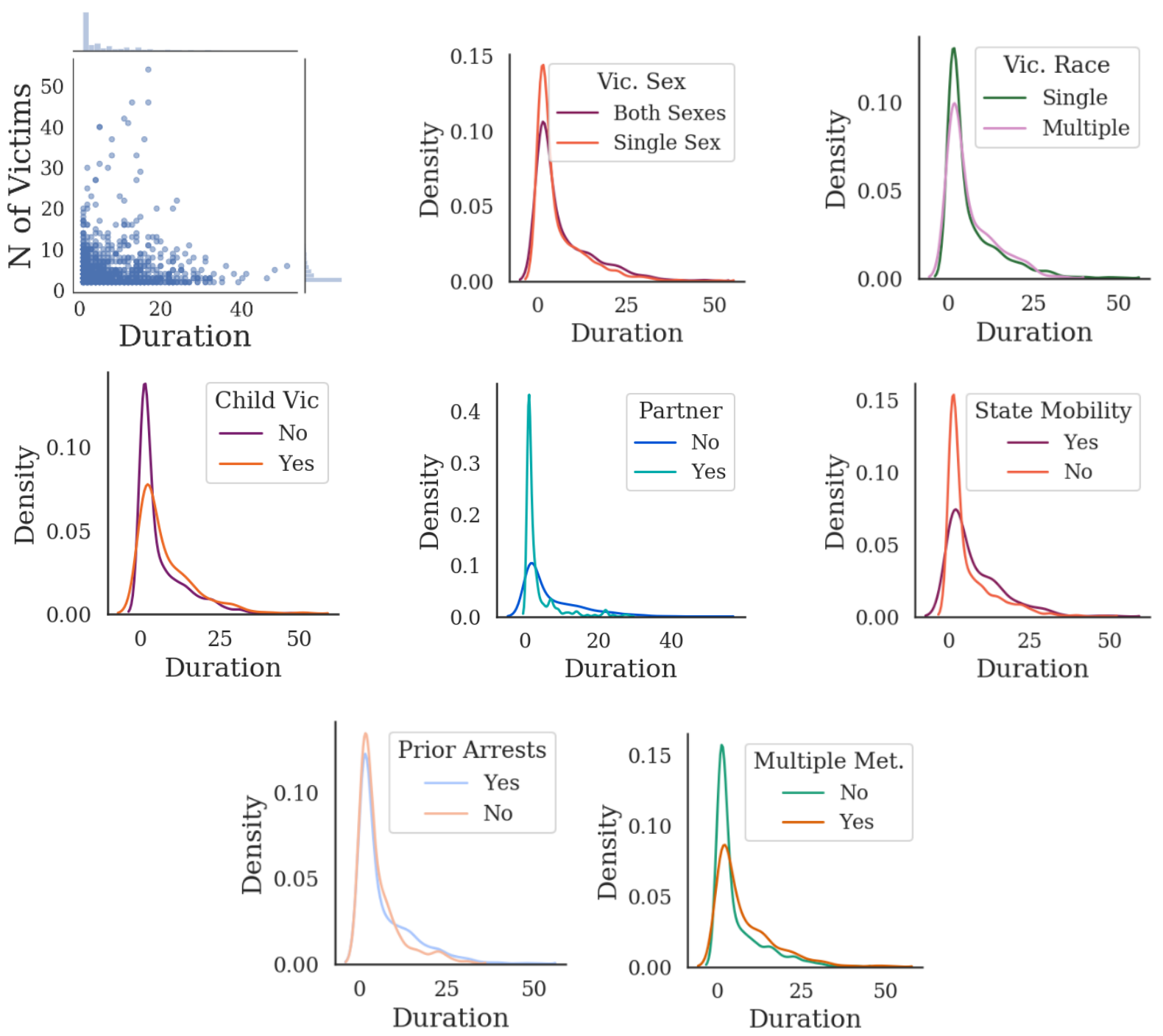

Figure 5: Career Duration Distribution by Criminal-related Attributes

The statistical outcomes of the table above indicate that also several career-based attributes correlate with the survival function of each individual. However, it is first worth noting that the number of victims (both in the non-transformed and in the quadratic form) does not seem to have any relationship with career duration, as the found coefficients are small and, foremost, non-significant. No effect is also found for victim's race: targeting only individuals from a single racial group does not increase or decrease the probability of a longer career, compared to those MHOs that target victims from multiple racial groups. Concerning the sex of the victims, those that kill victims of one gender have instead a $19 \%$ risk increase of career termination at each time step, compared to those who target victims of both sexes $(\mathrm{HR}=1.19 ; 95 \% \mathrm{CI}=1.06-1.35)$. Targeting children leads instead to a statistically significant $15 \%$ reduction in the risk of 
Table 5: Cox Regression Model - Career-based Attributes $(n=1,218)$

\begin{tabular}{|c|c|c|c|}
\hline Variable & $\begin{array}{l}\text { Coef. } \\
\text { (SE) }\end{array}$ & $\begin{array}{c}\text { Hazard } \\
\text { Ratio }\end{array}$ & $\begin{array}{c}\text { 95\% C.I. } \\
\text { Hazard Ratio }\end{array}$ \\
\hline \multicolumn{4}{|l|}{ Prolificity } \\
\hline$N$ of Victims & $-0.01(0.01)$ & 0.99 & {$[0.97-1.01]$} \\
\hline$N$ of Victims $* * 2$ & $-0.00(0.00)$ & 1.00 & {$[1.00-1.00]$} \\
\hline \multicolumn{4}{|l|}{ Victims' Race } \\
\hline Having Targeted Only a Single Race & $-0.01(0.07)$ & 0.99 & {$[0.87-1.12]$} \\
\hline \multicolumn{4}{|l|}{ Victims' Sex } \\
\hline Havng Targeted Only One Sex & $0.18^{\dagger}(0.08)$ & $1.19^{\dagger}$ & [1.06-1.35] \\
\hline \multicolumn{4}{|l|}{ Child Victim } \\
\hline Having Targeted at Least One Child & $-0.17^{* *}(0.07)$ & $0.85^{* *}$ & [0.73-0.99] \\
\hline \multicolumn{4}{|l|}{ Partner } \\
\hline Had Killing Partner & $0.68^{\dagger}(0.08)$ & $1.97^{\dagger}$ & {$[1.69-2.29]$} \\
\hline \multicolumn{4}{|l|}{ Methods } \\
\hline Having Used Multiple Methods & $-0.25^{\dagger}(0.06)$ & $0.78^{\dagger}$ & {$[0.69-0.88]$} \\
\hline \multicolumn{4}{|l|}{ Mobility } \\
\hline Having Killed in $>1$ US State & $-0.27^{\dagger}(0.07)$ & $0.76^{\dagger}$ & {$[0.67-0.87]$} \\
\hline \multicolumn{4}{|l|}{ Criminal background } \\
\hline Having been arrested before & $-0.13(0.09)$ & 0.88 & {$[0.74-1.04]$} \\
\hline Concordance & & 0.63 & \\
\hline Log-likelihood ratio test & & 59.89 on $6 \mathrm{df}$ & \\
\hline$-\log 2(p)$ of 11-ratio test & & 34.30 & \\
\hline
\end{tabular}

career termination at each time step $(\mathrm{HR}=0.85 ; 95 \% \mathrm{CI}=0.73-0.99)$. Large risk reductions have been found also for MHOs acting in more than one US state (HR $=0.76,95 \%$ $\mathrm{CI}=0.67-0.87)$ and for those employing multiple killing methods across their careers $(\mathrm{HR}=0.78 ; 95 \% \mathrm{CI}=0.69-0.88)$.

A potential explanation for these findings, as briefly anticipated in the Covariates subsection, might be the fact that being versatile in terms of behavior augments the difficulty of LEAs during investigations. For instance, those killing in multiple US states may benefit from the difficulties experienced by different LEAs in obtaining information and organizing effective investigations across jurisdictions. The opposite direction is found for those acting with a killing partner. The Hazard Ratio of 1.97 (95\% CI=1.692.29) indicates that those MHOs committing murders with partners have a $97 \%$ higher 


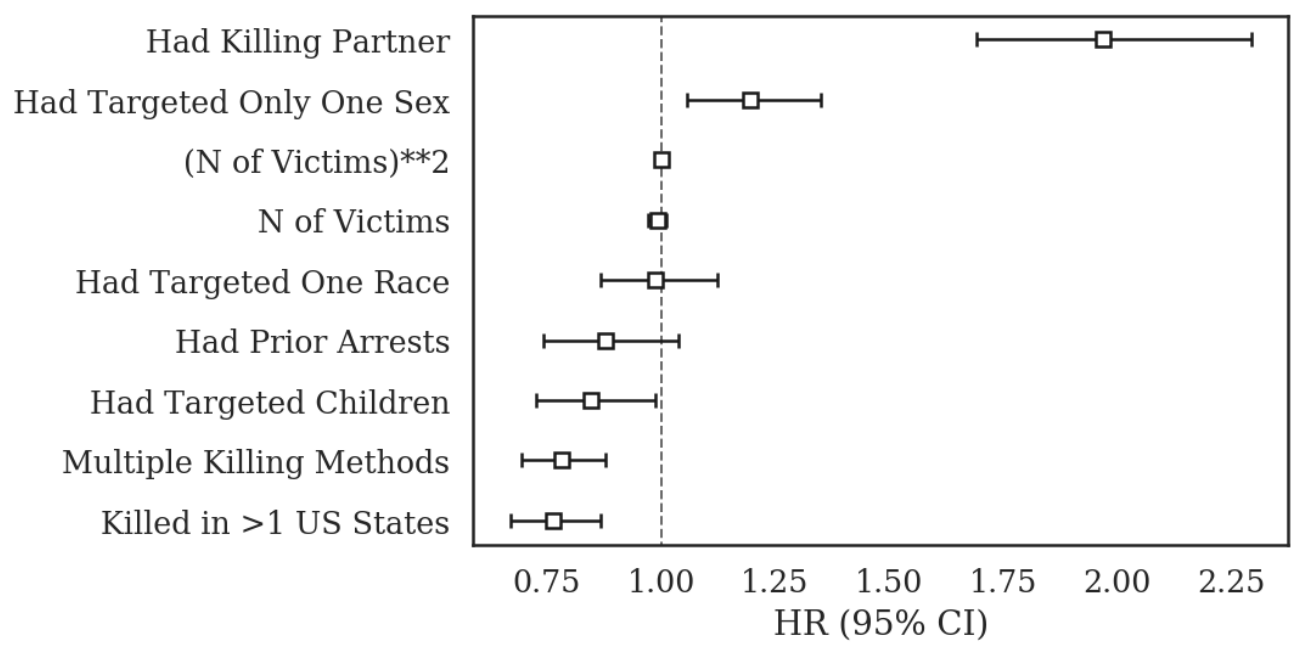

Figure 6: Effect Sizes of Hazard Ratio with 95\% C.I. (Career-based Attributes)

probability of career termination (at each time step, i.e., year) than those acting alone. Previous studies provided similar suggestions, although based on different samples or single case studies (Culhane et al., 2011; Gurian, 2017).

While solo offenders do not have to share their secretive criminal lifestyle with anyone, partnered MHOs inherently share their behavior and acts with at least one other person. This, first of all, increases the probability of defection in the team (e.g., suspects that decide to turn themselves in to the police) and also increases the probability of errors and the unwanted creation of forensic evidence.

\section{Inferential Analysis: Full Model}

The full model considers all the variables separately included in the previous ones, in order to comprehensively scan how the two information dimensions interact together in predicting the length of a career and avoid a spurious effect that may be due to omitted variables. As happened before, the number of victims failed the proportional hazard assumption, thus we have included quadratic and cubic terms. After subsequent testing, only the model with the cubic term passed the test. Regarding model selection, the one with no penalization appeared again to be the preferable one given the AIC scores (Table 6).

Most of the results found in the two previous separate models are confirmed in the full model, with few exceptions (Table 7). Among the exceptions, notably, when individual attributes and career-based characteristics are considered together, being a 
Table 6: AIC Results for Model Selection Across different Penalization Terms (Full Model) - Asterisk Highlights Best Model.

\begin{tabular}{cc}
\hline Penalization Term & AIC \\
\hline 0 & $14594.77^{*}$ \\
0.01 & 14596.59 \\
0.05 & 14603.48 \\
0.5 & 14653.86 \\
1 & 14682.04 \\
5 & 14736.96
\end{tabular}

male becomes strongly related to shorter careers. Specifically, at each time unit, being a male leads to an increase of the probability of career termination by $54 \%(\mathrm{HR}=1.54$; $95 \% \mathrm{CI}=1.21-1.91$ ), in line with similar results found by Gurian (2017). This translates into the finding that women, on average, prolong their offending activity much longer. While it is impossible to establish or reason about a causal mechanism (for this and all the other variables), this finding - coupled with others commented in the previous models - may indicate that, generally, MHOs whose characteristics are different from those of the dominant sub-groups tend to have more anomalous careers also in terms of duration. The age at first homicide can help in predicting career length. In fact, per each unit increase in the year at first homicide, there is a $2 \%$ increase probability in career termination ( $\mathrm{HR}=1.02 ; 95 \% \mathrm{CI}=1.01-1.02$ ). While younger MHOs have more years available to perpetuate their criminal behavior, making the finding not very surprising at first impact, it should be considered that younger offenders are also less expert, might be more disorganized, and eventually exhibit higher risks of being caught, as also pointed out by Myers (2004). In spite of these risks, however, the analyses reveal that they are able to act for statistically longer periods, compared to their older counterparts.

In the full model, the race of the offender is non-relevant in predicting or describing career duration, given the non-significance of the estimated coefficients, thus reducing the value of the finding presented in the individual-attributes model, with Hispanic MHOs reporting shorter careers. No results are also found for the number of victims, here included in a cubic form. With respect to victims' sex, targeting only victims of one sex again demonstrates to be a risk factor for early-career termination. Specifically, at each time unit, for every 100 MHOs targeting both women and men terminating 
their careers, there will be 115 MHOs targeting only either women or men concluding their killing trajectories $(\mathrm{HR}=1.15 ; 95 \% \mathrm{CI}=1.02-1.30)$. Finally, for what concerns the relation between victim's and MHOs, there is no relationship between having killed at least one child and the duration of the career, contrarily to what was found in the career-focused model (the direction of the coefficient remains stable, but the estimation here is non-significant).

Among the factors that are positively associated with longer careers are the tendency to use multiple killing methods, the mobility across US states and the presence of at least one arrest before the commission of the first murder. Those MHOs that murder their victims using different methods have a $24 \%$ risk reduction of career termination $(\mathrm{HR}=0.76 ; 95 \% \mathrm{CI}: 0.68-0.86)$ than those that only use one. Similarly, longer careers $(\mathrm{HR}=0.78 ; 95 \% \mathrm{CI}: 0.68-0.89)$ are experienced by MHOs that, throughout their careers, have committed murders traveling across at least two US states. This dynamic, as anticipated, may pose significant obstacles to investigations across LEAs based in different locations, hence facilitating the criminal plans of the offenders.

Finally, and somehow counter-intuitively, the presence of a previous arrest is associated with longer careers $(\mathrm{HR}=0.85 ; 95 \% \mathrm{CI}=0.71-1.02)$. Although individuals with prior records may be under the spotlight of LEAs, and thus subjected to stronger (and faster) scrutiny for their murders, these outcomes might instead suggest that the criminal skills and expertise developed in earlier phases of their lives might be assets to prolong their activity as MHOs. Finally, the presence of a killing partner confirms to be strongly associated with shorter careers. At each time unit, the probability of career termination is $98 \%$ higher $(\mathrm{HR}=1.98,95 \% \mathrm{CI}: 1.70-2.30)$ for those that act with a partner compared to those acting alone. Figure 7 graphically displays these results. It is worth noting the particularly high magnitude of the coefficients related to the presence of a killing partner and the fact of being a male. 
Table 7: Cox Regression Model - Full/All the attributes $(n=1,207)$

\begin{tabular}{|c|c|c|c|}
\hline Variable & $\begin{array}{l}\text { Coef. } \\
\text { (SE) }\end{array}$ & $\begin{array}{c}\text { Hazard } \\
\text { Ratio }\end{array}$ & $\begin{array}{c}\text { 95\% C.I. } \\
\text { Hazard Ratio }\end{array}$ \\
\hline \multicolumn{4}{|l|}{ Sex } \\
\hline Male & $0.43 \dagger(0.12$ & $1.54 \dagger$ & {$[1.21-1.91]$} \\
\hline \multicolumn{4}{|l|}{ Age } \\
\hline Age at First Homicide & $0.02 \dagger(0.00)$ & $1.02 \dagger$ & {$[1.01-1.02]$} \\
\hline \multicolumn{4}{|l|}{ Race (Baseline is "White") } \\
\hline Black & $0.01(0.07)$ & 1.01 & {$[0.88-1.15]$} \\
\hline Hispanic & $0.21(0.14)$ & 1.24 & {$[0.94-1.63]$} \\
\hline Other & $-0.20(0.14)$ & 0.82 & {$[0.53-1.28]$} \\
\hline \multicolumn{4}{|l|}{ Prolificity } \\
\hline$N$ of Victims $* * 3$ & $-0.00(0.00)$ & 1.00 & {$[1.00-1.00]$} \\
\hline \multicolumn{4}{|l|}{ Victims' Race } \\
\hline Having Targeted Only a Single Race & $0.01(0.07)$ & 1.01 & {$[0.88-1.15]$} \\
\hline \multicolumn{4}{|l|}{ Victims' Sex } \\
\hline Havng Targeted Only One Sex & $0.14 * *(0.06)$ & $1.15^{* *}$ & {$[1.02-1.30]$} \\
\hline \multicolumn{4}{|l|}{ Child Victim } \\
\hline Having Targeted at Least One Child & $-0.09(0.08)$ & 0.91 & {$[0.78-1.07]$} \\
\hline \multicolumn{4}{|l|}{ Partner } \\
\hline Had Killing Partner & $0.68^{\dagger}(0.08)$ & $1.98^{\dagger}$ & {$[1.70-2.30]$} \\
\hline \multicolumn{4}{|l|}{ Methods } \\
\hline Having Used Multiple Methods & $-0.27^{\dagger}(0.06)$ & $0.76^{\dagger}$ & {$[0.68-0.86]$} \\
\hline \multicolumn{4}{|l|}{ Mobility } \\
\hline Having Killed in $>1$ US State & $-0.25^{\dagger}(0.07)$ & $0.78^{\dagger}$ & {$[0.68-0.89]$} \\
\hline \multicolumn{4}{|l|}{ Criminal background } \\
\hline Having been arrested before & $-0.17 *(0.09)$ & $0.85^{*}$ & {$[0.71-1.02]$} \\
\hline Concordance & & 0.65 & \\
\hline Log-likelihood ratio test & & 9.84 on 1 & \\
\hline$-\log 2(\mathrm{p})$ of ll-ratio test & & 95.34 & \\
\hline
\end{tabular}




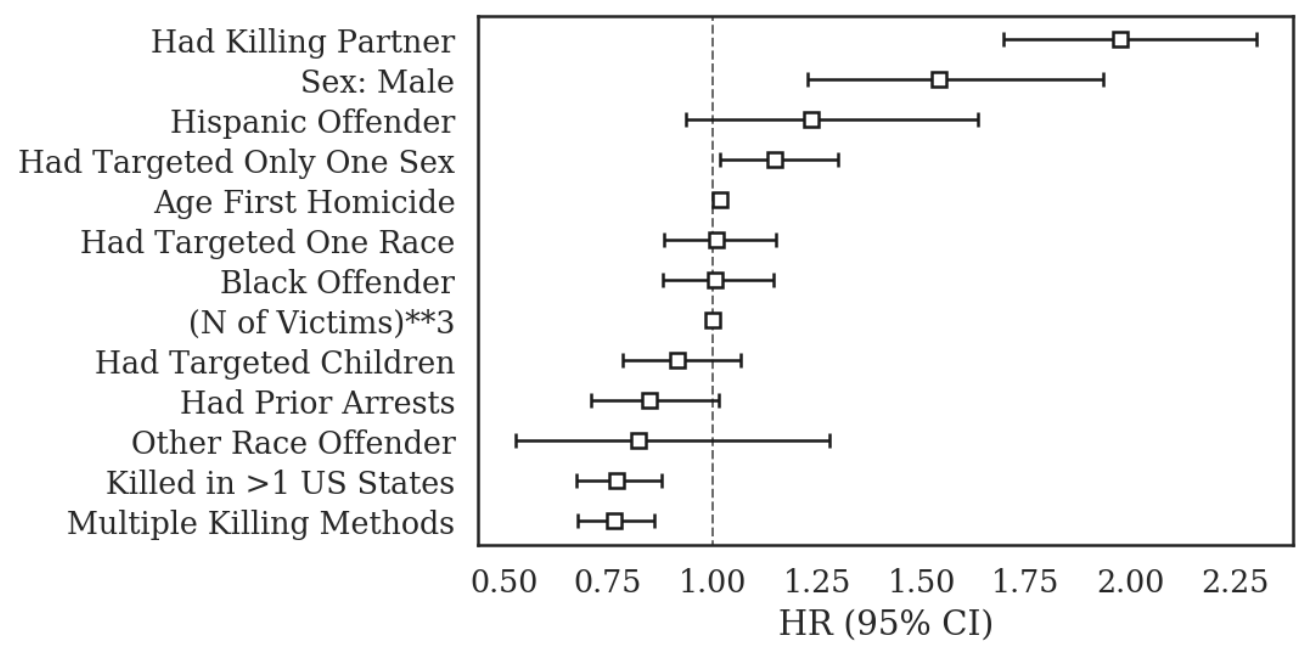

Figure 7: Effect Sizes of Hazard Ratio with 95\% C.I. (Full Model)

\section{Discussion and Conclusions}

MHOs represent a spectacularized offending niche that is deeply embedded in media and culture. Notwithstanding the popularity of this category of offenders, most of the dominating public narratives on the topic are based on myths or wrongful information (Hickey, 2015; Hodgkinson et al., 2017).

In order to advance the understanding of MHOs and help to reverse the related misinformed discourse, empirical research is of paramount importance. This work sought to provide a contribution in this sense. Specifically, it attempted to gain better knowledge of MHOs by analyzing the duration of their careers and the factors that correlate with such duration. By employing data from the Consolidated Serial Homicide Offender Database, we have retrieved a sample of 1,394 MHOs based in the US and investigated what influences the length of a killing career. Through the use of survival analysis, we have first performed a univariate analysis looking at career length alone. The result showed a median duration of 3 years, and an average of 6.47. The high variation in duration within the sample (standard deviation of 7.67 years) suggested the potential presence of underlying factors affecting the number of years of activity per each offender. Therefore, we have carried out three separate inferential models: the first focused on the role of individual-level attributes on career duration, the second included covariates pertaining to the criminal features of the individual. Finally, the third one combined both dimensions together. Several consistent results emerge. 
When controlling for criminal career features, the model shows that men experience significantly shorter careers compared to women. In the full model, they report a $43 \%$ increase in career termination at each time unit (i.e., year), given the $H R=1.43$. Concerning age, those who start to kill earlier face a higher probability of longer careers. In fact, a unit increase in the age at first homicide leads to a $2 \%$ increase in career termination. Hispanic MHOs report significance in their shorter duration only in the individual-level attribute model $(\mathrm{HR}=1.33)$. The significance vanishes when criminal features are included in the equation.

Several criminal attributes are correlated with career duration as well. If one only targets victims of a specific sex (i.e., either only men or women), each year they will report a $15-18 \%$ risk increase (career-attributes model $\mathrm{HR}=1.18$, full model $\mathrm{HR}=1.15$ ) of career termination compared to those targeting victims of multiple sexes. A consistent negative effect on career duration has been found also for those MHOs acting with a partner. In the career-focused model, the OR was equal to 1.97 , slightly increased to 1.98 in the full model. Conversely, positive effects on career duration have been highlighted for MHOs acting in at least two US states (career-focused model HR $=0.76$, full model $\mathrm{HR}=0.78$ ) and for those employing multiple methods to carry out their killing activity (career-attributes model $\mathrm{HR}=0.78$, full model $\mathrm{HR}=0.76$ ). Moreover, in the full model, having been arrested before the first homicide highlighted a significant correlation with higher career duration $(\mathrm{HR}=0.85)$. The relation, however, while sharing the same direction was not significant in the career-attributes model. Coupled with the weak significance in the full one, this calls for caution in interpreting its statistical strength as a result. Finally, no significant effects on career duration were reported for the number of victims, the presence of at least a child victim and the tendency to target victims belonging to a single racial group.

Finally, no significant effects on career duration were reported for the number of victims, the presence of at least a child victim and the tendency to target victims belonging to a single racial group.

While almost all the reported findings show a strong statistical strength, it is worth noting that this study comes with two relevant limitations. First, the selected sample of US-based MHOs might not be representative of the same dynamics occurring in other countries. The duration of a career is certainly a consequence of the offenders' choices, 
but other entities intervene in the process. The criminal justice system and LEAs taking part in the investigative process are also extremely relevant in potentially influencing the length of a criminal career. Therefore, heterogeneity across countries in terms of LEA practices and resources, for instance, might lead to different outcomes. Hence, further studies focusing on non-US samples are required to corroborate the outcomes presented in this work. Second, the covariates included in the inferential models do not take into account psychological and biological variables. Research has widely demonstrated the relevance of considering these dimensions in describing and predicting criminal behavior (Raine, 1992; Brennan and Raine, 1997; Cauffman et al., 2005), also in relation to serial murder (Stone, 2001; Hill et al., 2007; Hickey et al., 2018). Due to the lack of reliable and sufficient data on mental issues, abuse, cognitive abilities in this dataset, we were forced to rely only on socio-demographic information. Although we expect the presented results to hold also in additional models, it would be critical to complement the findings of this study with further information on psychological and biological accounts.

Despite these limitations, however, the present work seeks to gather a deeper knowledge of an overlooked aspect of MHO's activity, namely their career duration. It attempts to do so by testing a methodology that is well-established in many disciplines, including criminology, proposing its use for further studies on the same topic. Career duration is not solely an academic-relevant topic. Shedding light on the correlates related to the duration of an MHO career can be extremely relevant also for practical investigative aims. While searching for an MHO, in fact, LEAs generally have a set of incomplete information regarding the author in terms of socio-demographic data or, more often, information on their modus operandi and committed homicides. Relying on this or similar future studies, an agency can develop probabilistic estimates of career duration based on their available information, and thus act in response to these estimates by allocating investigative resources or developing effective communication strategies with the communities they are embedded in. While every career is different and these models do not claim to establish any causal relationship between the tested covariates and career duration, being able to draw upon the findings of solid methodologies may be a relevant support for police investigative efforts. Furthermore, one of the findings of the models, namely the longer career duration of MHOs acting in multiple US states, specif- 
ically calls for the improvement of collaboration, information sharing and coordination across local and federal agencies and different jurisdictions.

\section{Competing Interests}

The authors declare no competing interests.

\section{Funding}

The authors did not receive any funding for the present research.

\section{Code and Data Availability}

The code and data used to perform the analyses presented in this paper will be shared on the GitHub page of the corresponding author after the work is accepted for journal publication. In the meanwhile, those who are interested can contact the corresponding author by email. 


\section{References}

Akaike, H. (1974). A new look at the statistical model identification. IEEE Transactions on Automatic Control, 19(6):716-723. Conference Name: IEEE Transactions on Automatic Control.

Arndt, W. B., Hietpas, T., and Kim, J. (2004). Critical characteristics of male serial murderers. American Journal of Criminal Justice, 29(1):117-131.

Beasley, J. O. (2004). Serial murder in America: case studies of seven offenders. Behavioral Sciences \& the Law, 22(3):395-414.

Beauregard, E. and Martineau, M. (2014). No body, no crime? The role of forensic awareness in avoiding police detection in cases of sexual homicide. Journal of Criminal Justice, 42(2):213-220.

Beauregard, E., Stone, M. R., Proulx, J., and Michaud, P. (2008). Sexual Murderers of Children: Developmental, Precrime, Crime, and Postcrime Factors. International Journal of Offender Therapy and Comparative Criminology, 52(3):253-269. Publisher: SAGE Publications Inc.

Benda, B. B. (2005). Gender Differences in Life-Course Theory of Recidivism: A Survival Analysis. International Journal of Offender Therapy and Comparative Criminology, 49(3):325-342. Publisher: SAGE Publications Inc.

Blumstein, A. and Cohen, J. (1987). Characterizing Criminal Careers. Science, 237(4818):985-991. Publisher: American Association for the Advancement of Science Section: Articles.

Box-Steffensmeier, J. M., Cunha, R. C., Varbanov, R. A., Hoh, Y. S., Knisley, M. L., and Holmes, M. A. (2015). Survival Analysis of Faculty Retention and Promotion in the Social Sciences by Gender. PLOS ONE, 10(11):e0143093. Publisher: Public Library of Science.

Branson, A. L. (2013). African American Serial Killers: Over-Represented Yet Underacknowledged. The Howard Journal of Criminal Justice, 52(1):1-18. _eprint: https://onlinelibrary.wiley.com/doi/pdf/10.1111/j.1468-2311.2012.00731.x. 
Brennan, P. A. and Raine, A. (1997). Biosocial bases of antisocial behavior: Psychophysiological, neurological, and cognitive factors. Clinical Psychology Review, 17(6):589604.

Campedelli, G. M., Calderoni, F., Comunale, T., and Meneghini, C. (2019). LifeCourse Criminal Trajectories of Mafia Members. Crime \& Delinquency, page 001112871986083.

Canter, D. and Larkin, P. (1993). The environmental range of serial rapists. Journal of Environmental Psychology, 13(1):63-69. Place: Netherlands Publisher: Elsevier Science.

Cauffman, E., Steinberg, L., and Piquero, A. R. (2005). Psychological, Neuropsychological and Physiological Correlates of Serious Antisocial Behavior in Adolescence: The Role of Self-Control*. Criminology, 43(1):133-176. _eprint: https://onlinelibrary.wiley.com/doi/pdf/10.1111/j.0011-1348.2005.00005.x.

Chan, H. C. O., Myers, W. C., and Heide, K. M. (2010). An Empirical Analysis of 30 Years of U.S. Juvenile and Adult Sexual Homicide Offender Data: Race and Age Differences in the Victim-Offender Relationship. Journal of Forensic Sciences, 55(5):1282-1290. _eprint: https://onlinelibrary.wiley.com/doi/pdf/10.1111/j.1556-4029.2010.01448.x.

Council, N. R. (2009). Strengthening Forensic Science in the United States: A Path Forward. National Academies Press. Google-Books-ID: 6clxAgAAQBAJ.

Cox, D. R. (1972). Regression Models and Life-Tables. Journal of the Royal Statistical Society: Series B (Methodological), 34(2):187-202. _eprint: https://rss.onlinelibrary.wiley.com/doi/pdf/10.1111/j.2517-6161.1972.tb00899.x.

Culhane, S. E., Hilstad, S. M., Freng, A., and Gray, M. J. (2011). Selfreported psychopathology in a convicted serial killer. Journal of Investigative Psychology and Offender Profiling, 8(1):1-21. _eprint: https://onlinelibrary.wiley.com/doi/pdf/10.1002/jip.129.

Darmofal, D. (2009). Bayesian Spatial Survival Models for Political Event 
Processes. American Journal of Political Science, 53(1):241-257. _eprint: https://onlinelibrary.wiley.com/doi/pdf/10.1111/j.1540-5907.2008.00368.x.

Davidson-Pilon, C., Kaldestarm, J., Jacobson, N., Kuhn, B., Zivich, P., Williamson, M., Abdeali, J., Datta, D., Fiore-Gartland, A., Parij, A., Wilson, D., Gabriel, Moneda, L., Stark, K., Moncada-Torres, A., Harsh, G., Jona, Karthikeyan, S., Besson, L., Sancho Peña, M., Anton, S., Klintberg, A., Noorbakhsh, J., Begun, M., Kumar, R., Hussey, S., Golland, D., and Flaxman, A. (2020). Lifelines.

DeFronzo, J., Ditta, A., Hannon, L., and Prochnow, J. (2007). Male Serial Homicide: The Influence of Cultural and Structural Variables. Homicide Studies, 11(1):3-14. Publisher: SAGE Publications Inc.

DeLisi, M. (2015). Mayhem by Occupation. In Sex Offenders, pages 219-229. John Wiley \& Sons, Ltd. Section: 10 eprint: https://onlinelibrary.wiley.com/doi/pdf/10.1002/9781118314630.ch10.

DeLisi, M., Ruelas, M., and Kruse, J. E. (2019). Who will kill again? The forensic value of 1st degree murder convictions. Forensic Science International: Synergy, 1:11-17.

Delisi, M. and Scherer, A. M. (2006). Multiple Homicide Offenders: Offense Characteristics, Social Correlates, and Criminal Careers. Criminal Justice and Behavior, 33(3):367-391.

Egger, S. A. (1997). The Killers Among Us: An Examination of Serial Murder and Its Investigation. Prentice Hall, Upper Saddle River, NJ.

Farrington, D. P., Ttofi, M. M., Crago, R. V., and Coid, J. W. (2014). Prevalence, frequency, onset, desistance and criminal career duration in self-reports compared with official records. Criminal Behaviour and Mental Health, 24(4):241-253. _eprint: https://onlinelibrary.wiley.com/doi/pdf/10.1002/cbm.1930.

Fox, J. A. and Levin, J. (1994). Overkill: Mass Murder and Serial Killing Exposed. Springer Verlag, New York, softcover reprint of the original 1st ed. 1994 edizione edition.

Fox, J. A. and Levin, J. (1998). Multiple Homicide: Patterns of Serial and Mass Murder. Crime and Justice, 23:407-455. Publisher: The University of Chicago Press. 
Fridel, E. E. (2019). Female Serial Killers. In The Encyclopedia of Women and Crime, pages 1-2. American Cancer Society. _eprint: https://onlinelibrary.wiley.com/doi/pdf/10.1002/9781118929803.ewac0167.

Giot, P. and Schwienbacher, A. (2007). IPOs, trade sales and liquidations: Modelling venture capital exits using survival analysis. Journal of Banking \& Finance, 31(3):679702.

Golub, J. (2007). Survival Analysis and European Union Decision-making. European Union Politics, 8(2):155-179. Publisher: SAGE Publications.

Greenfield, L. A. (1996). Child Victimizers: Violent Offenders and Their Victims. Bureau of Justice Statistics Clearinghouse, Box 179, Annapolis Junction, MD 20701-0179.

Gurian, E. A. (2017). Reframing Serial Murder Within Empirical Research: Offending and Adjudication Patterns of Male, Female, and Partnered Serial Killers. International Journal of Offender Therapy and Comparative Criminology, 61(5):544-560. Publisher: SAGE Publications Inc.

Hanson, R. K., Steffy, R. A., and Gauthier, R. (1993). Long-term recidivism of child molesters. Journal of Consulting and Clinical Psychology, 61(4):646-652. Place: US Publisher: American Psychological Association.

Harbort, S. and Mokros, A. (2001). Serial Murderers in Germany from 1945 to 1995: A Descriptive Study. Homicide Studies. Publisher: Sage Publications.

Hickey, E. W. (2015). Serial Murderers and Their Victims. Wadsworth Pub Co, Boston, MA, USA, 7 edizione edition.

Hickey, E. W., Walters, B. K., Drislane, L. E., Palumbo, I. M., and Patrick, C. J. (2018). Deviance at its darkest: Serial murder and psychopathy. In Handbook of psychopathy, 2nd ed, pages 570-584. The Guilford Press, New York, NY, US.

Hill, A., Habermann, N., Berner, W., and Briken, P. (2007). Psychiatric Disorders in Single and Multiple Sexual Murderers. Psychopathology, 40(1):22-28. Publisher: Karger Publishers. 
Hjort, N. L. (1992). On Inference in Parametric Survival Data Models. International Statistical Review / Revue Internationale de Statistique, 60(3):355-387. Publisher: [Wiley, International Statistical Institute (ISI)].

Hodgkinson, S., Prins, H., and Stuart-Bennett, J. (2017). Monsters, madmen... and myths: A critical review of the serial killing literature. Aggression and Violent Behavior, $34: 282-289$.

Häkkänen-Nyholm, H., Putkonen, H., Lindberg, N., Holi, M., Rovamo, T., and Weizmann-Henelius, G. (2009). Gender differences in Finnish homicide offence characteristics. Forensic Science International, 186(1):75-80.

James, J. and Beauregard, E. (2020). Murderer vs investigator: factors influencing the resolution of sexual homicide cases. Police Practice and Research, 21(2):172-186.

James, J., Beauregard, E., and Proulx, J. (2019). Sexual murderers in everyday life. Journal of Criminal Justice, 60:64-73.

Jenkins, P. (1994). Using Murder: The Social Construction of Serial Homicide. Routledge, New York, 1 edizione edition.

Juodis, M., Woodworth, M., Porter, S., and Ten Brinke, L. (2009). Partners in Crime: A Comparison of Individual and Multi-perpetrator Homicides. Criminal Justice and Behavior, 36(8):824-839. Publisher: SAGE Publications Inc.

Kaplan, E. L. and Meier, P. (1958). Nonparametric Estimation from Incomplete Observations. Journal of the American Statistical Association, 53(282):457-481. Publisher: Taylor \& Francis _eprint: https://www.tandfonline.com/doi/pdf/10.1080/01621459.1958.10501452.

Keeney, B. T. and Heide, K. M. (1994). Gender Differences in Serial Murderers: A Preliminary Analysis. Journal of Interpersonal Violence, 9(3):383-398. Publisher: SAGE Publications Inc.

Kelleher, M. D. and Kelleher, C. L. (1998). Murder most rare: The female serial killer. Murder most rare: The female serial killer. Praeger Publishers/Greenwood Publishing Group, Westport, CT, US. Pages: xii, 213. 
Kelty, S. F., Julian, R., and Ross, A. (2013). Dismantling the Justice Silos: Avoiding the pitfalls and reaping the benefits of information-sharing between forensic science, medicine and law. Forensic Science International, 230(1):8-15.

Kraemer, G. W., Lord, W. D., and Heilbrun, K. (2004). Comparing single and serial homicide offenses. Behavioral Sciences \& the Law, 22(3):325-343. _eprint: https://onlinelibrary.wiley.com/doi/pdf/10.1002/bsl.581.

Laitinen, E. K. (2005). Survival Analysis and Financial Distress Prediction: Finnish Evidence. Review of Accounting and Finance, 4(4):76-90. Publisher: Emerald Group Publishing Limited.

Lambert, P. C. and Royston, P. (2009). Further Development of Flexible Parametric Models for Survival Analysis. The Stata Journal, 9(2):265-290. Publisher: SAGE Publications.

Lange, R. (1999). A Cusp Catastrophe Approach to the Prediction of Temporal Patterns in the Kill Dates of Individual Serial Murderers. Nonlinear Dynamics, Psychology, and Life Sciences, 3(2):143-159.

LePard, D., Demers, S., Langan, C., and Kim Rossmo, D. (2015). Challenges in serial murder investigations involving missing persons. Police Practice and Research, $16(4): 328-340$.

Liem, M. (2013). Homicide offender recidivism: A review of the literature. Aggression and Violent Behavior, 18(1):19-25.

MacKenzie, T., Gifford, A. H., Sabadosa, K. A., Quinton, H. B., Knapp, E. A., Goss, C. H., and Marshall, B. C. (2014). Longevity of Patients With Cystic Fibrosis in 2000 to 2010 and Beyond: Survival Analysis of the Cystic Fibrosis Foundation Patient Registry. Annals of Internal Medicine, 161(4):233-241. Publisher: American College of Physicians.

Marshall, D. B. and English, D. J. (1999). Survival Analysis of Risk Factors for Recidivism in Child Abuse and Neglect. Child Maltreatment, 4(4):287-296. Publisher: SAGE Publications Inc. 
Mathews, S., Abrahams, N., Jewkes, R., Martin, L. J., and Lombard, C. (2013). The epidemiology of child homicides in South Africa. Bulletin of the World Health Organization, 91(8):562-568.

Miller, L. (2014). Serial killers: I. Subtypes, patterns, and motives. Aggression and Violent Behavior, 19(1):1-11.

Mitchell, H. and Aamodt, M. G. (2005). The incidence of child abuse in serial killers. Journal of Police and Criminal Psychology, 20(1):40-47. Company: Springer Distributor: Springer Institution: Springer Label: Springer Number: 1 Publisher: Springer US.

Morton, R., Tillman, J., and Gaines, S. (2014). Serial Murder: Pathways for Investigations. Technical report, Justice Department - Federal Bureau of Investigation.

Myers, W. C. (2004). Serial murder by children and adolescents. Behavioral Sciences \& the Law, 22(3):357-374. _eprint: https://onlinelibrary.wiley.com/doi/pdf/10.1002/bsl.590.

Osborne, J. R. and Salfati, C. G. (2014). Re-Conceptualizing "Cooling-Off Periods" in Serial Homicide:. Homicide Studies. Publisher: SAGE PublicationsSage CA: Los Angeles, CA.

Pakhomou, S.-M. (2004). Serial Killers: Offender's Relationship to the Victim and Selected Demographics. International Journal of Police Science \& Management, 6(4):219-233. Publisher: SAGE Publications Ltd.

Pakkanen, T., Zappalà, A., Bosco, D., Berti, A., and Santtila, P. (2015). Can hardto-solve one-off homicides be distinguished from serial homicides? Differences in offence behaviours and victim characteristics. Journal of Criminal Psychology, 5:216232.

Piquero, A. R., Brame, R., and Lynam, D. (2004). Studying Criminal Career Length Through Early Adulthood Among Serious Offenders. Crime \& Delinquency, 50(3):412-435. Publisher: SAGE Publications Inc. 
Piquero, A. R., Farrington, D. P., and Blumstein, A. (2007). Key Issues in Criminal Career Research: New Analyses of the Cambridge Study in Delinquent Development. Cambridge University Press. Google-Books-ID: OPnXXkrmJA0C.

Quinet, K. (2011). Prostitutes as Victims of Serial Homicide: Trends and Case Characteristics, 1970-2009. Homicide Studies, 15(1):74-100. Publisher: SAGE Publications Inc.

Raine, A. (1992). Schizotypal and borderline features in psychopathic criminals. Personality and Individual Differences, 13(6):717-721.

Reale, K. and Beauregard, E. (2019). Body Recovery After the "First 48": Implications for Sexual Homicide Investigations. Homicide Studies, 23(2):126-144.

Rhodes, W. (1989). The criminal career: Estimates of the duration and frequency of crime commission. Journal of Quantitative Criminology, 5(1):3-32.

Royston, P. and Parmar, M. K. B. (2002). Flexible parametric proportional-hazards and proportional-odds models for censored survival data, with application to prognostic modelling and estimation of treatment effects. Statistics in Medicine, 21(15):21752197. _eprint: https://onlinelibrary.wiley.com/doi/pdf/10.1002/sim.1203.

Rulli, E., Ghilotti, F., Biagioli, E., Porcu, L., Marabese, M., D’Incalci, M., Bellocco, R., and Torri, V. (2018). Assessment of proportional hazard assumption in aggregate data: a systematic review on statistical methodology in clinical trials using time-to-event endpoint. British Journal of Cancer, 119(12):1456-1463. Number: 12 Publisher: Nature Publishing Group.

Salfati, C. G. and Bateman, A. L. (2005). Serial homicide: an investigation of behavioural consistency. Journal of Investigative Psychology and Offender Profiling, 2(2):121-144.

Salfati, C. G., Labuschagne, G. N., Horning, A. M., Sorochinski, M., and Wet, J. D. (2015). South African Serial Homicide: Offender and Victim Demographics and Crime Scene Actions. Journal of Investigative Psychology and Offender Profiling, 12(1):18-43. _eprint: https://onlinelibrary.wiley.com/doi/pdf/10.1002/jip.1425. 
Schlesinger, L. B., Ramirez, S., Tusa, B., Jarvis, J. P., and Erdberg, P. (2017). RapidSequence Serial Sexual Homicides. The Journal of the American Academy of Psychiatry and the Law, 45(1):72-80.

Singh, R. and Mukhopadhyay, K. (2011). Survival analysis in clinical trials: Basics and must know areas. Perspectives in Clinical Research, 2(4):145-148.

Smith, L. G. and Akers, R. L. (1993). A Comparison of Recidivism of Florida's Community Control and Prison: A Five-Year Survival Analysis. Journal of Research in Crime and Delinquency, 30(3):267-292. Publisher: SAGE Publications Inc.

Snook, B., Cullen, R. M., Mokros, A., and Harbort, S. (2005). Serial murderers' spatial decisions: factors that influence crime location choice. Journal of Investigative Psychology and Offender Profiling, 2(3):147-164. _eprint: https://onlinelibrary.wiley.com/doi/pdf/10.1002/jip.35.

Spehr, A., Hill, A., Habermann, N., Briken, P., and Berner, W. (2010). Sexual Murderers With Adult or Child Victims: Are They Different? Sexual Abuse, 22(3):290-314. Publisher: SAGE Publications Inc.

Stone, M. H. (2001). Serial Sexual Homicide: Biological, Psychological, and Sociological Aspects. Journal of Personality Disorders, 15(1):1-18. Publisher: Guilford Publications Inc.

Sturup, J. (2018). Comparing serial homicides to single homicides: A study of prevalence, offender, and offence characteristics in Sweden. Journal of Investigative Psychology and Offender Profiling, 15(2):75-89. _eprint: https://onlinelibrary.wiley.com/doi/pdf/10.1002/jip.1500.

Stöckl, H., Dekel, B., Morris-Gehring, A., Watts, C., and Abrahams, N. (2017). Child homicide perpetrators worldwide: a systematic review. BMJ Paediatrics Open, 1(1):e000112. Publisher: BMJ Specialist Journals Section: Child Abuse.

Trojan, C. and Salfati, C. G. (2010). Comparing the Criminal History Profiles of Serial and Single-Victim Homicide Offenders. Victims \& Offenders, 6(1):38-63. Publisher: Routledge_eprint: https://doi.org/10.1080/15564886.2011.534008. 
Trojan, C. and Salfati, G. (2016). Criminal history of homicide offenders: a multidimensional analysis of criminal specialization. Journal of Criminal Psychology, 6(1):28-41. Publisher: Emerald Group Publishing Limited.

Vatcheva, K., Lee, M., McCormick, J., and Rahbar, M. (2015). The Effect of Ignoring Statistical Interactions in Regression Analyses Conducted in Epidemiologic Studies: An Example with Survival Analysis Using Cox Proportional Hazards Regression Model. Epidemiology (Sunnyvale, Calif.), 6(1).

Vaughn, M. G., DeLisi, M., Beaver, K. M., and Howard, M. O. (2009). Multiple murder and criminal careers: A latent class analysis of multiple homicide offenders. Forensic Science International, 183(1):67-73.

Widom, C. S. (1989). Child Abuse, Neglect, and Adult Behavior. American Journal of Orthopsychiatry, 59(3):355-367. _eprint: https://onlinelibrary.wiley.com/doi/pdf/10.1111/j.1939-0025.1989.tb01671.x.

Williams, D. (2017a). Entering the Minds of Serial Murderers: The Application of Forensic Leisure Science to Homicide Research. Leisure Sciences, 39(4):376-383.

Williams, D. J. (2017b). Mephitic projects: a forensic leisure science analysis of the BTK serial murders. The Journal of Forensic Psychiatry \& Psychology, 28(1):24-37.

Wilschanski, M., Chait, P., Wade, J. A., Davis, L., Corey, M., Louis, P. S., Griffiths, A. M., Blendis, L. M., Moroz, S. P., Scully, L., and Roberts, E. A. (1995). Primary sclerosing cholangitis in 32 children: Clinical, laboratory, and radiographic features, with survival analysis. Hepatology, 22(5):1415-1422. _eprint: https://aasldpubs.onlinelibrary.wiley.com/doi/pdf/10.1002/hep.1840220513.

Yaksic, E. (2015). Addressing the challenges and limitations of utilizing data to study serial homicide. Crime Psychology Review, 1(1):108-134.

Yaksic, E. (2019). Moving past sporadic eruptions, discursive killing, and running amok: recognizing the convergence of the serial and spree killer. Journal of Criminal Psychology, 9(3):138-146. 